\section{An unusual case of refractory asthma}

\section{CLINICAL PRESENTATION}

A 34-year-old woman with atopic asthma since the age of 16 years presented with increasing exertional dyspnoea and wheeze over a period of 12 months. She had no symptomatic benefit from escalation of bronchodilator therapy and her peak expiratory flow (PEF) remained reduced despite multiple courses of oral corticosteroid. Lung function at rest showed mild air flow obstruction with forced expiratory volume in $1 \mathrm{~s}\left(\mathrm{FEV}_{1}\right)$ of 2.271 $(75 \%$ predicted), forced vital capacity (FVC) of $3.131(89 \%$ predicted) and a $\mathrm{FEV}_{1} / \mathrm{FVC}$ ratio of $73 \%$. Both inspiratory and expiratory limbs of the flow-volume loop (FVL) had a flattened appearance. She was also noted to have a right-sided aortic knuckle on chest x-ray.

To determine the mechanisms of exercise limitation, she underwent an incremental cardiopulmonary exercise test on a cycle ergometer with maximal FVL measured during exercise. Her exercise performance was limited by breathlessness, achieving a peak work rate of 77 Watts (55\% predicted) and a peak oxygen uptake of $1.171 / \mathrm{min}$ (61\% predicted). Endexercise minute ventilation was $49.11 / \mathrm{min}$ ( $62 \%$ of predicted maximal voluntary ventilation), indicating a normal breathing reserve. However, the ventilatory pattern was abnormal with over-reliance on respiratory frequency ( 52 breaths/min at peak exercise) and restriction in tidal volume $(0.831$ at peak exercise). In addition, the maximal FVL changed during exercise (figure 1).

\section{QUESTION}

What is the diagnosis?

See page 74 for answer

\section{Wai-Ting Nicola Lee ${ }^{1}$, Aileen Brown², Steve Banham',} Hamish Walker ${ }^{3}$, Martin Johnson ${ }^{1}$

${ }^{1}$ Department of Respiratory Medicine, Gartnavel General Hospital, Glasgow, UK; ${ }^{2}$ Respiratory Laboratory, Gartnavel General Hospital, Glasgow, UK; ${ }^{3}$ Scottish Adult Congenital Cardiac Service, Golden Jubilee National Hospital, Glasgow, UK

Correspondence to Dr Wai-Ting Nicola Lee, Department of Respiratory Medicine, Gartnavel General Hospital, 1053 Great Western Road, Glasgow G12 OYN, UK; waiting.lee@nhs.net

Competing interests None.

Patient consent Obtained

Provenance and peer review Not commissioned; externally peer reviewed.

Published Online First 19 November 2010

Thorax 2011;66:54. doi:10.1136/thx.2010.139212
Figure 1 Maximal flow-volume loops performed during incremental cardiopulmonary exercise test showed that, during exercise, peak inspiratory flow (PIF) fell from $5.1 \mathrm{l} / \mathrm{s}$ at rest to $3.2 \mathrm{l} / \mathrm{s}$ and peak expiratory flow (PEF) from $3.36 \mathrm{l} / \mathrm{s}$ at rest to $2.35 \mathrm{l} / \mathrm{s}$. This inspiratory and expiratory flow limitation led to a $20 \%$ reduction in both forced expiratory volume in $1 \mathrm{~s}$ and inspiratory capacity during exercise. PIF and PEF returned to resting values at recovery.

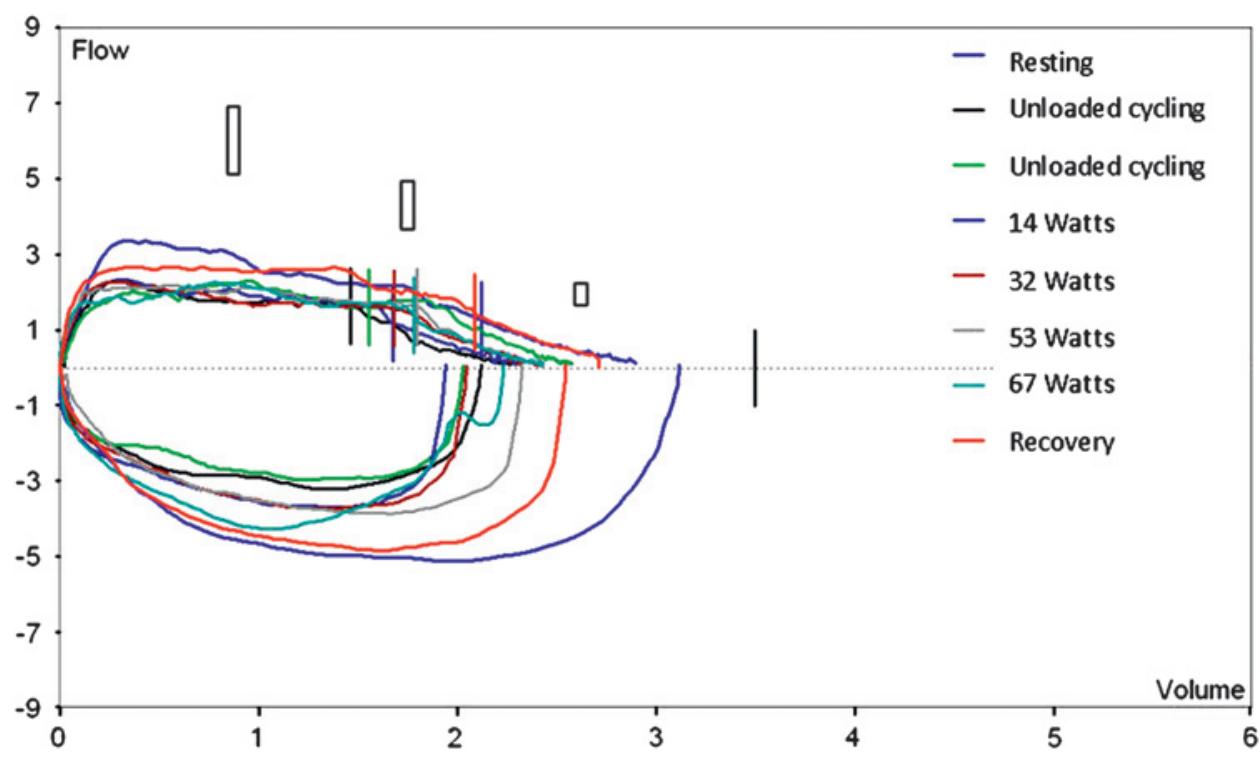




\section{ANSWER}

From the question on page 54

A CT scan showed a double aortic arch forming a complete vascular ring encircling the trachea (figure $2 \mathrm{~A}, \mathrm{~B}$ ). This caused extrinsic compression at rest with worsening during exercise leading to both inspiratory and expiratory flow limitation. After surgical division of the vascular ring her peak work rate increased to 124 Watts (89\% predicted) and peak oxygen uptake to $1.43 \mathrm{l} /$ $\min (75 \%$ predicted). When comparing isotime ventilatory parameters before and after surgery at 77 Watts (peak work rate achieved before surgery), there was a reduction in respiratory frequency (from 52 breaths/min to 39 breaths $/ \mathrm{min}$ ) and an improvement in tidal volume (from 0.831 vs to 1.021 ). The maximal FVL during exercise after surgery was improved with no significant fall in peak inspiratory flow (PIF), PEF, $\mathrm{FEV}_{1}$ or inspiratory capacity (IC) compared with resting values (figure 3 ).

Primary presentation of a congenital complete vascular ring in adulthood is unusual as it is likely to cause severe symptoms in infancy or early childhood leading to diagnosis. ${ }^{1-3}$ Increased tracheal compression during exercise is thought to be caused by aortic dilatation due to increased arterial pressure. The ascending aorta dilates by $1 \mathrm{~mm}$ or more for every $15 \mathrm{~mm} \mathrm{Hg}$ increase in systolic or diastolic pressure, so exercise may add a further 3-6 mm of circumferential tracheal constriction. ${ }^{45}$

As upper airway obstruction is relatively uncommon, a high index of suspicion is required to make the diagnosis. Flowvolume loops at rest may provide the first clue to the presence of upper airway obstruction. If this is confirmed radiologically by CT scanning, an incremental cardiopulmonary exercise test with maximal FVL measurement may be useful in providing a detailed assessment of the ventilatory response to exercise preand post-intervention as demonstrated in this case.

Thorax 2011;66:74. doi:10.1136/thx.2010.139212

\section{REFERENCES}

1. Fadel E, Chapelier AR, Cerrina J, et al. Vascular ring causing symptomatic tracheal compression in adulthood. Ann Thorac Surg 1995;60:1411-13.

2. Grathwohl KW, Afifi AY, Dillard TA, et al. Vascular rings of the thoracic aorta in adults. Am Surg 1999:65:1077-83.

3. Greiner A, Perkmann $\mathrm{R}$, Rieger $\mathrm{M}$, et al. Vascular ring causing tracheal compression in an adult patient. Ann Thorac Surg 2003;75:1959-60.

4. Isnard RN, Pannier BM, Laurent S, et al. Pulsatile diameter and elastic modulus of the aortic arch in essential hypertension: a noninvasive study. J Am Coll Cardiol 1989:13:399-405.

5. Merillon JP, Motte G, Fruchaud J, et al. Evaluation of the elasticity and characteristic impedance of the ascending aorta in man. Cardiovasc Res 1978;12:401-6.
Figure $2(A, B)$ Three-dimensional reconstruction $\mathrm{CT}$ scan showing the anatomy of the complete vascular ring. $A A$, ascending aorta; RAA, right aortic arch; RSA, right subclavian artery, RCCA, right common carotid artery; LCCA, left common carotid artery; LSA, left subclavian artery; LAA, left aortic arch; DA, descending aorta; $T$, trachea; $C$, carina.
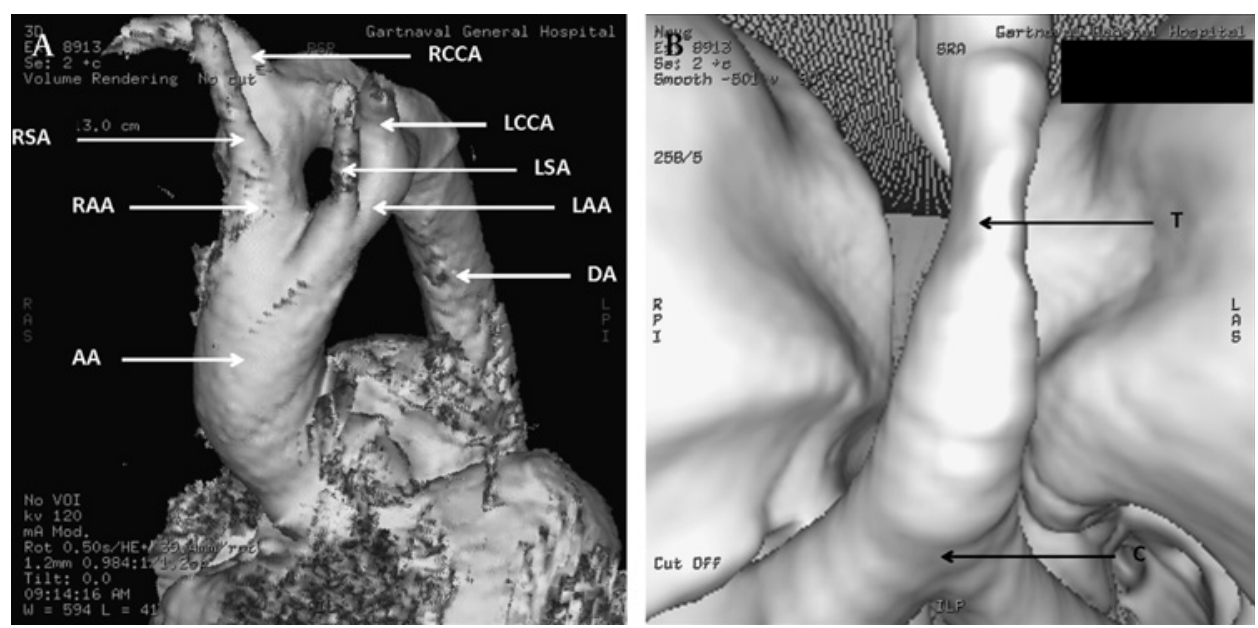

Figure 3 Maximal flow-volume loops performed during incremental cardiopulmonary exercise test after surgery.

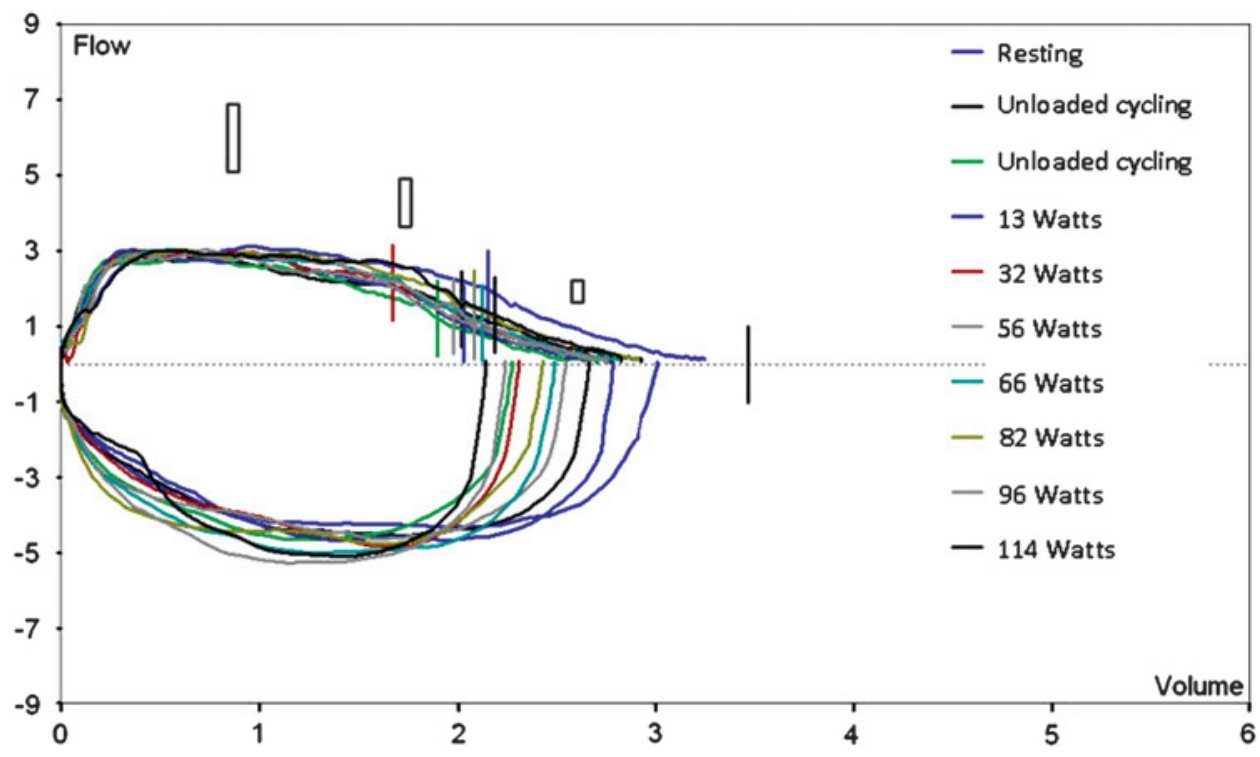

